МОРФОМЕТРИЧЕСКАЯ ХАРАКТЕРИСТИКА ХРОНИЧЕСКОЙ ТОКСИЧНОСТИ ПРИ ЧАСТОМ ПОВТОРНОМ ВВЕДЕНИИ МЕСТНЫХ АНЕСТЕТИКОВ ГРУППЫ АМИДОВ В ЭКСПЕРИМЕНТЕ

\author{
МАКСИМОВИЧ Е.В., ПОХОДЕНЬКО-ЧУДАКОВА И.О.
}

Белорусский государственный медицинский университет, г.Минск, Республика Беларусь

Вестник ВГМУ. - 2016. - Том 15, №5. - С. 91-97.

\title{
MORPHOMETRIC CHARACTERISTIC OF CHRONIC TOXICITY ON FREQUENT REPEATED EXPERIMENTAL ADMINISTRATION OF AMIDES GROUP LOCAL ANESTHETICS
}

\author{
MAKSIMOVICH E.V., POKHODENKO-CHUDAKOVA I.O. \\ Belarusian State Medical University, Minsk, Republic of Belarus
}

Vestnik VGMU. 2016;15(5):91-97.

\begin{abstract}
Резюме.
Цель - исследовать хроническую токсичность местных анестетиков (МА) группы амидов в эксперименте, определить эффективность электрорефлексотерапии для профилактики хронической токсической реакции. Материал и методы. Эксперимент выполнен на 9 сериях лабораторных мышей, которым каждые 3-4 дня 5 раз субмандибулярно или внутрибрюшинно вводили МА. Затем проводили морфометрическое исследование паренхиматозных органов. Сравнивали серии: с введением 2\% раствора лидокаина гидрохлорида субмандибулярно (серии 1.1, 1.3), внутрибрюшинно (серии 1.2, 1.4); с введением 4\% раствора артикаина гидрохлорида субмандибулярно (серии 2.1, 2.3), внутрибрюшинно (серии 2.2, 2.4). В серии 3 (контроль) субмандибулярно вводили воду для инъекций. Сериям 1.3, 1.4, 2.3, 2.4 перед введением МА проводили по 5 процедур электрорефлексотерапии.

Результаты. По данным морфометрии в сериях 1.1, 2.1 выявлено достоверно больше мелких, средних некрозов, воспалительных изменений в портальных трактах, холестаза, клеточного полиморфизма, чего нет в сериях 1.2, 2.2, 3. Из клеток воспалительного инфильтрата преобладали клетки лимфоидного ряда. В сериях 1.3, 2.3 достоверно меньше мелких, средних некрозов, воспалительных изменений в портальных трактах, случаев холестаза, отсутствовали большие некрозы. При сравнительной оценке морфологических изменений серий 1.2, 2.2 и 1.4, 2.4 было выявлено достоверно значимое уменьшение числа мелких некрозов. Заключение. Результаты свидетельствуют о влиянии зоны введения МА на развитие токсических реакций и доказывают, что при введении МА в область головы и шеи электрорефлексотерапия способна оказывать достоверный гепатопротективный эффект.
\end{abstract}

Ключевые слова: местные анестетики, токсичность, морфометрия.

\begin{abstract}
.
Objectives. To study chronic toxicity of local anesthetics (LA) of the amides group in the experiment, to determine the effectiveness of electroreflexotherapy for the prevention of chronic toxic reaction.

Material and methods. The experiment was carried out on 9 series of laboratory mice which were given submandibular or intraperitoneal injections of LA every 3-4 days 5 times. Then we performed the morphometric examination of the parenchymal organs. We compared the series: with submandibular injection of $2 \%$ lidocaine hydrochloride solution (series 1.1, 1.3), intraperitoneally (series 1.2, 1.4); with submandibular injection of 4\% articaine hydrochloride solution (series 2.1, 2.3), intraperitoneally (series 2.2, 2.4). Series 3 (control) got submandibular injections of water for injections. Series 1.3, 1.4, 2.3, 2.4 had 5 procedures of electroreflexotherapy prior to the introduction of the LA. Results. According to the morphometry data, in series 1.1, 2.1 we revealed significantly more small, moderate necroses, inflammatory changes in portal tracts, cases of cholestasis, cell polymorphism that was not found in
\end{abstract}


series $1.2,2.2,3$. The cells of the lymphoid range dominated among the cells of inflammatory infiltrate. In series 1.3, 2.3 there were significantly fewer small, medium necroses, inflammatory changes in portal tracts, cases of cholestasis, there were no big necroses. A comparative evaluation of morphological changes of series $1.2,2.2$ and $1.4,2.4$ revealed a statistically significant decrease in the number of small necroses.

Conclusions. The results indicate the influence of the LA injection zone on the development of toxic reactions and prove that when injecting LA in the head and neck area, electroreflexotherapy is able to provide reliable hepatoprotective effect.

Key words: local anesthetics, toxicity, morphometry.

Местные анестетики (МА) группы амидов в настоящее время наиболее часто используются для обезболивания стоматологических вмешательств. Как правило, стоматологическим пациентам при санации полости рта местное инъекционное обезболивание с применением МА группы амидов проводится ежедневно. Об опасности токсических концентраций МА в крови при выполнении регионарной анестезии неоднократно сообщалось в периодических и научных изданиях $[1,2]$.

Однако до настоящего времени специальная медицинская литература не располагает данными об исследовании местных анестетиков на предмет хронической токсичности, в том числе и средств, используемых с указанной целью в повседневной стоматологической практике. Кроме того, МА на предмет токсичности до настоящего времени тестируются стандартным методом внутрибрюшинного введения [3].

В научной литературе встречались только единичные сообщения, содержащие сведения о том, что МА, используемые в стоматологической практике, следует тестировать внутриротовым способом введения [4].

Лекарственные поражения печени - это патологические изменения в ткани органа, вызванные применением лекарственных средств. При этом тип поражения печени зависит от свойств препарата, его дозы, исходного состояния пациента [5]. Известно, что МА группы амидов метаболизизуются в печени с образованием биоактивных гепатотоксичных метаболитов и, следовательно, могут способствовать развитию хронических токсических реакций [6].

Таким образом, каждый из перечисленных фактов, как и все они в совокупности, обосновывают целесообразность предпринятого исследования и подтверждают актуальность избранной темы.
Цель работы - исследовать хроническую токсичность местных анестетиков группы амидов в эксперименте, определить эффективность электрорефлексотерапии для профилактики хронической токсической реакции.

\section{Материал и методы}

Эксперимент выполнен на сериях белых лабораторных мышей, используемых для определения токсичности лекарственных средств, половозрелых самцах массой 22-35 грамм, полученных из питомника Центральной научно-исследовательской лаборатории учреждения образования «Белорусский государственный медицинский университет», прошедших двухнедельный карантин и содержащихся на стандартном рационе вивария со свободным доступом к пище и воде.

Экспериментальные исследования проводили в соответствии с правилами, регламентирующими работу с экспериментальными животными [7, 8], и были одобрены комитетом по биоэтике учреждения образования «Белорусский государственный медицинский университет».

Сравнивали данные серий экспериментальных животных по 10-12 особей в каждой: с введением 2\% раствора лидокаина гидрохлорида субмандибулярно и внутрибрюшинно лабораторным белым мышам (серии 1.1 и 1.2, соответственно); с введением 4\% раствора артикаина гидрохлорида с адреналином $1: 200$ 000 субмандибулярно и внутрибрюшинно лабораторным белым мышам (серии 2.1 и 2.2, соответственно).

С целью исключения морфологических изменений печени непосредственно в ответ на введение МА (инъекции) была исследована серия 3 с введением в поднижнечелюстную область воды для инъекций в строгом соответствии с планом экспериментального исследо- 
вания, соблюдая те же сроки введения. Данная серия служила контролем.

Соответственно, серии с введением МА $1.1,1.2,2.1,2.2$ сравнивались и с серией 3 , особям которой вводилась вода для инъекций.

С целью минимизации хронических токсических реакций, возникающих при частых повторных введениях МА, перед введением МА был проведен курс рефлексотерапии (электронейростимуляции) в соответствии с системой соответствия су-джок на область ладонных поверхностей конечностей лабораторных белых мышей, что соответствует проекции печени, сердца, а также области головы и шеи. Перед введением МА субмандибулярно и внутрибрюшинно каждой особи серий $1.3,1.4$, 2.3, 2.4 было проведено по 5 процедур рефлексотерапии.

Особям серии 1.3 вводили $2 \%$ раствор лидокаина гидрохлорида субмандибулярно, серии 1.4 - внутрибрюшинно. Особям серии 2.3 вводился 4\% раствор артикаина гидрохлорида субмандибулярно, серии 2.4 - внутрибрюшинно. Данные серии сравнивались между собой.

Терапевтические дозы МА рассчитывались на единицу массы тела животного исходя из данных клинической фармакологии [9].

После выведения животных из эксперимента на каждом из этапов последнего осуществляли забор паренхиматозных органов на патоморфологическое исследование с целью выявления наиболее чувствительных к токсическому действию органов и систем организма, а также определения степени их повреждения.

Забранный патоморфологический материал фиксировали в 10\% растворе нейтрального формалина, проводили по стандартной схеме через спирты восходящей концентрации и заключали в гистомикс. Изготовленные серийные гистологические срезы окрашивали гематоксилином-эозином с последующим заключением в бальзам. Гистологические препараты были исследованы при помощи светового микроскопа «Leica DM 2500» при увеличении $\mathrm{x} 200, \mathrm{x} 400$. Для определения количественных характеристик полученных морфологических данных и их статистической оценки было проведено морфометрическое исследование по стандартной методике серийных срезов. Было исследовано каждое пятое поле зрения каждого пятого среза каждого пятого стекла в каждой серии экспериментального исследования [10].
Статистическую обработку данных проводили с помощью программы «Statistica 10.0», использовались непараметрические методы: четырехпольные таблицы, коэффициент Фишера, хи-квадрат $\left(\chi^{2}\right)$. Различия цифровых показателей считали статистически значимыми при $\mathrm{p}<0,05$ [11].

\section{Результаты}

К проявлениям хронической токсической реакции, связанной с частым повторным введением МА из группы амидов, относили такие морфологические изменения, как очаги некроза гепатоцитов, которые были разделены на мелкие - 1-4 клетки и 4-6 клеток; средние - 6-8 и 8-12 клеток и крупные - 12 клеток и более [12]. Все очаги некроза сопровождались перифокальной воспалительной инфильтрацией, представленной в основном лимфоцитами, единичными эозинофилами и нейтрофилами. Воспалительная инфильтрация портальных трактов была представлена в основном лимфоцитами. Отмечался перипортальный холестаз, в некоторых срезах - центролобулярный холестаз; лимфоцитарный васкулит вокруг центральных вен (рис. 1, 2).

Также при морфологическом исследовании определялся клеточный полиморфизм (рис. 3), фиброз. К явлениям клеточного полиморфизма относили: разные размеры гепатоцитов, разные размеры ядер гепатоцитов, клеточный анизоцитоз и анизонуклеоз. Однако количественной оценке эти изменения не подвергались.

При сравнении серий 1.1, 1.2, 3 (введение $2 \%$ раствора лидокаина гидрохлорида) было выявлено отсутствие патологических морфологических изменений печени у особей серии 1.1 в 32,5\% (13) наблюдений, в то время как при внутрибрюшинном введении у особей серии 1.2 изменения отсутствовали в 70,0\% (49) наблюдений, при введении воды для инъекций (серия 3) изменения отсутствовали в $68,3 \%$ (41) наблюдений $(\mathrm{p}=0,000)$.

Морфометрически в серии 1.1 выявлено достоверно $(p=0,000)$ большее число мелких и средних некрозов, наблюдались большие некрозы, чего не было выявлено в сериях 1.2 и 3 , большее число воспалительных изменений в портальных трактах, чаще - холестаз. Из клеток воспалительного инфильтрата преоб- 


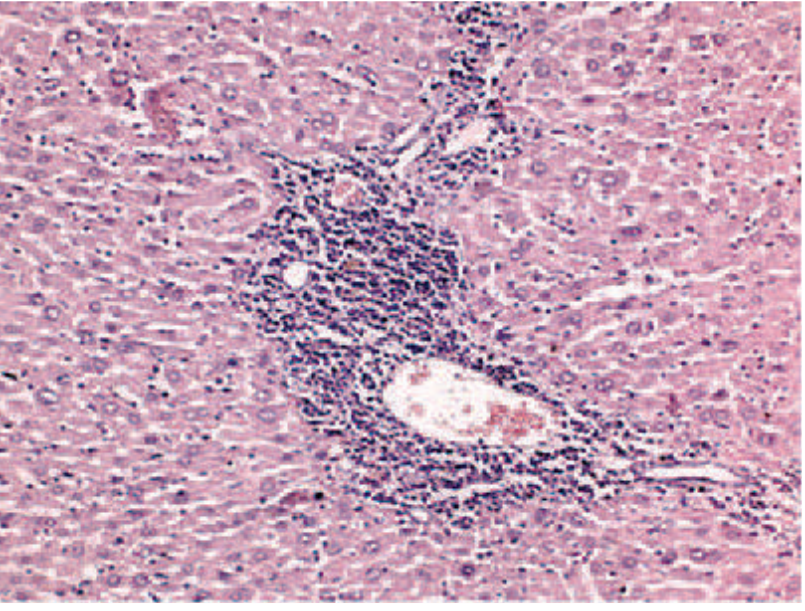

Рисунок 1 - Инфильтрация перипортального тракта у особей серии 1.1 .

Окраска гематоксилин-эозин, увеличение х400.

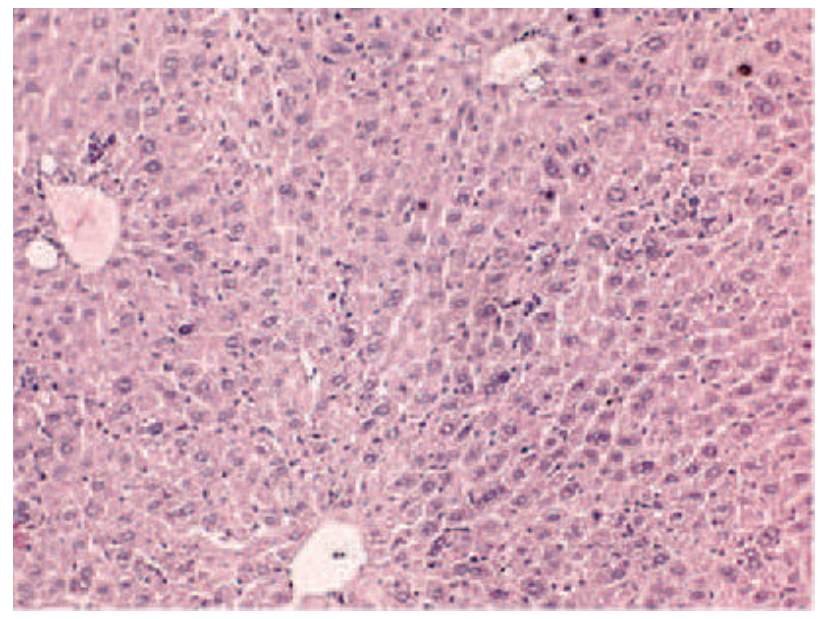

Рисунок 3 - Клеточный полиморфизм гепатоцитов у особей серии 1.1. Окраска гематоксилин-эозин, увеличение $\mathrm{x} 400$.

ладали клетки лимфоидного ряда, примесь нейтрофилов и эозинофилов была не велика. В отдельных срезах в серии 1.1 также определялся клеточный полиморфизм.

При сравнении результатов морфометрического исследования в сериях, где вводили 4\% раствора артикаина гидрохлорида, было отмечено, что у особей серии 2.1 в 42,5\% (34) наблюдений не регистрировались патологические морфологические изменения печени, в то время как при внутрибрюшинном введении (серия 2.2) изменения отсутствовали в $74,4 \%$ (67) наблюдений, при введении воды для инъекций (серия 3) изменения отсутствовали в $68,3 \%$ (41) наблюдений ( $\mathrm{p}=0,000)$ (табл. 1).

Морфометрически в серии 2.1 выявлено

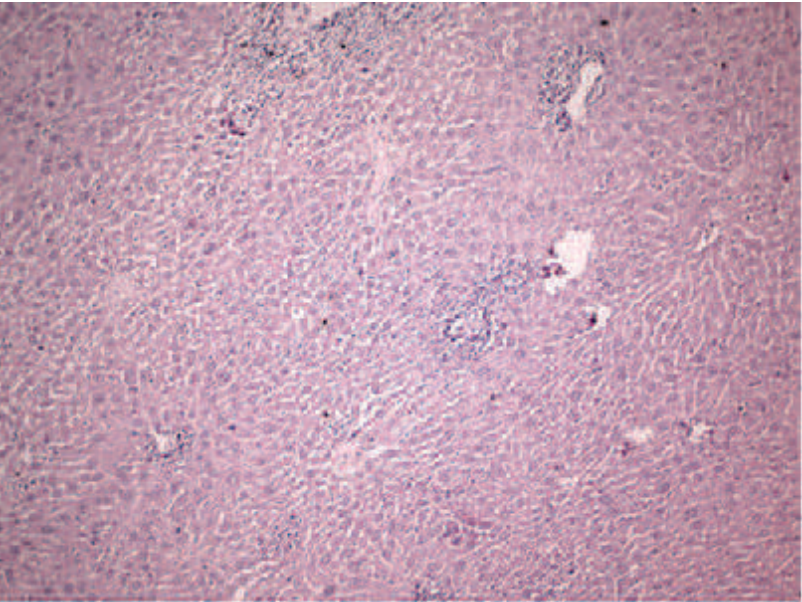

Рисунок 2 - Очаги некроза гепатоцитов у особей серии 1.1.

Окраска гематоксилин-эозин, увеличение х200.

достоверно большее число мелких некрозов (при сравнении с серией $3 \mathrm{p}=0,000$ и $\mathrm{p}=0,034-\mathrm{c}$ серией 2.2), средних некрозов ( $\mathrm{p}=0,000)$, наблюдались большие некрозы, чего не было выявлено в сериях 2.2 и 3 , значительно более выраженные воспалительные изменения в портальных трактах $(\mathrm{p}=0,000)$ и холестаз $(\mathrm{p}=0,020)$ (табл. 2). Среди клеток воспалительного инфильтрата преобладали клетки лимфоидного ряда, нейтрофилы и эозинофилы определялись в незначительном количестве. В отдельных срезах в серии 2.1 определялся клеточный полиморфизм, белковая дистрофия гепатоцитов, скопления клеток воспалительного ряда в синусоидах. Только при введении 4\% раствора артикаина гидрохлорида в область головы и шеи были выявлены явления васкулита, что может быть объяснено фармакологическими свойствами данного МА и влиянием адреналина.

На основании представленного материала можно сделать вывод, что частые повторные введения 4\% раствора артикаина гидрохлорида в область головы и шеи более токсичны в сравнении с внутрибрюшинным введением и введением воды для инъекций. Выявлено статистически значимое влияние на проявления хронической токсичности области введения лекарственного средства.

При сравнении серий 1.1 и 1.3 (особям которых проводилась рефлексотерапия) при введении 2\% раствора лидокаина гидрохлорида субмандибулярно у особей серии 1.1 в 32,5\% (13) наблюдений не регистрировались патологические морфологические изменения печени, 
в то время как у животных, которым предварительно проводилась рефлексотерапия (серия 1.3), изменения отсутствовали в 58,1\% (93) наблюдений $(\mathrm{p}=0,003)$.

Морфометрически у особей серии 1.3 выявлено достоверно меньшее число мелких некрозов ( $\mathrm{p}=0,000)$, средних некрозов $(\mathrm{p}=0,000)$, отсутствовали большие некрозы, было значительно менее выраженные воспалительные инфильтративные изменения в портальных трактах $(\mathrm{p}=0,000)$ и уменьшение случаев холестаза $(\mathrm{p}=0,000)$ (табл. 1$)$.

Соответственно, все изложенные выше факты свидетельствуют о гепатопротективном эффекте рефлексотерапии.

При сравнении морфологических изменений в сериях, особям которых 2\% раствор лидокаина гидрохлорида вводился внутрибрюшинно (серии 1.2, 1.4), было выявлено только достоверное снижение числа мелких некрозов.

При сравнении морфологических изменений в сериях, особям которых вводился 4\% раствора артикаина гидрохлорида, было выявлено, что у особей серии 2.1 в 42,5\% (34) наблюдений патологических морфологических изменений печени не констатировали, в то время как у особей, которым предварительно проводилась электронейростимуляция (серия $2.3)$, изменения отсутствовали в 74,4\% (67) наблюдений $(\mathrm{p}=0,000)$.

Морфометрически в серии 2.3 выявлено достоверно меньшее число мелких некрозов $(p=0,000)$, средних некрозов $(p=0,000)$, отсутствовали большие некрозы, было выявлено значительно менее выраженные воспалительные инфильтративные изменения в портальных трактах $(p=0,000)$ и меньшее число явле-

Таблица 1 - Данные сравнительной морфометрической оценки препаратов серий 1.1, 1.2, $1.3,3$

\begin{tabular}{|l|c|c|c|c|}
\hline \multicolumn{1}{|c|}{ Вид патологии } & Серия 1.1 & Серия 1.2 & Серия 1.3 & Серия 3 \\
\hline Нет изменений & $32,5 \%(93)$ & $70,0 \%(49)$ & $58,1 \%(49)$ & $68,3 \%(41)$ \\
\hline Некроз 1-4 клеток & $102,5 \%(66)$ & $27,1 \%(19)$ & $41,3 \%(66)$ & $21,7 \%(13)$ \\
\hline Некроз 4-6 клеток & $0,0 \%(0)$ & $2,9 \%(2)$ & $5,0 \%(8)$ & $6,7 \%(4)$ \\
\hline Некроз 6-8 клеток & $12,5 \%(5)$ & $0,0 \%(0)$ & $1,9 \%(3)$ & $1,7 \%(1)$ \\
\hline Некроз 8-12 клеток & $2,5 \%(1)$ & $1,4 \%(1)$ & $0,0 \%(0)$ & $0,0 \%(0)$ \\
\hline Некроз 12-20 клеток & $2,5 \%(1)$ & $0,0 \%(0)$ & $0,0 \%(0)$ & $0,0 \%(0)$ \\
\hline $\begin{array}{l}\text { Инфильтрация портальных } \\
\text { трактов }\end{array}$ & $60,0 \%(24)$ & $12,9 \%(9)$ & $17,5 \%(28)$ & $11,7 \%(7)$ \\
\hline Холестаз & $57,5 \%(23)$ & $2,9 \%(2)$ & $3,1 \%(5)$ & $10,0 \%(6)$ \\
\hline Васкулит & $0,0 \%(0)$ & $0,0 \%(0)$ & $0,0 \%(0)$ & $0,0 \%(0)$ \\
\hline
\end{tabular}

Примечание: \% высчитывался от исходного числа полей зрения; более $100 \%$ означает, что в одном поле зрения определяли более одного некроза.

Таблица 2 - Данные сравнительной морфометрической оценки препаратов серий 2.1, 2.2, $2.3,3$

\begin{tabular}{|l|c|c|c|c|}
\hline \multicolumn{1}{|c|}{ Вид патологии } & Серия 2.1 & Серия 2.2 & Серия 2.3 & Серия 3 \\
\hline Нет изменений & $42,5 \%(34)$ & $62,5 \%(25)$ & $74,4 \%(67)$ & $68,3 \%(41)$ \\
\hline Некроз 1-4 клеток & $43,8 \%(35)$ & $45,0 \%(18)$ & $24,4 \%(22)$ & $21,7 \%(13)$ \\
\hline Некроз 4-6 клеток & $28,3 \%(19)$ & $2,5 \%(1)$ & $13,3 \%(12)$ & $6,7 \%(4)$ \\
\hline Некроз 6-8 клеток & $16,3 \%(13)$ & $5,0 \%(2)$ & $2,2 \%(2)$ & $1,7 \%(1)$ \\
\hline Некроз 8-12 клеток & $18,8 \%(15)$ & $0,0 \%(0)$ & $1,1 \%(1)$ & $0,0 \%(0)$ \\
\hline Некроз 12-20 клеток & $6,3 \%(5)$ & $0,0 \%(0)$ & $0,0 \%(0)$ & $0,0 \%(0)$ \\
\hline $\begin{array}{l}\text { Инфильтрация портальных } \\
\text { трактов }\end{array}$ & $58,8 \%(47)$ & $15,0 \%(6)$ & $17,8 \%(16)$ & $11,7 \%(7)$ \\
\hline Холестаз & $28,8 \%(23)$ & $10,0 \%(4)$ & $4,4 \%(4)$ & $10,0 \%(6)$ \\
\hline Васкулит & $8,8 \%(7)$ & $0,0 \%(0)$ & $1,1 \%(1)$ & $0,0 \%(0)$ \\
\hline
\end{tabular}

Примечание: \% высчитывался от исходного числа полей зрения; более $100 \%$ означает, что в одном поле зрения определяли более одного некроза. 
ний холестаза $(\mathrm{p}=0,00)$. Перечисленные факты также указывают на гепатопротективный эффект рефлексотерапии (табл. 2).

При сравнительной оценке морфологических изменений у особей серий 2.2 и 2.4 было выявлено только достоверно значимое снижение числа мелких некрозов.

\section{Обсуждение}

Согласно данным специальной литературы клинико-морфологическими вариантами лекарственных гепатопатий являются: некроз гепатоцитов III зоны ацинуса; некроз гепатоцитов I зоны ацинуса; митохондриальная цитопатия; лекарственно-индуцированный фиброз печени; лекарственный стеатогепатит; острый и хронический лекарственные гепатиты; поражение печени по типу реакции гиперчувствительности; лекарственный канальцевый, паренхиматозно-канальцевый и внутрипротоковый холестаз; лекарственноиндуцированный склерозирующий холангит; лекарственно-индуцированный билиарный сладж; поражение сосудов печени (расширение синусоидов, пелиоз, веноокклюзионная болезнь, обструкция воротной и печеночной вен), лекарственно-индуцированные опухоли печени $[13,14,15]$. Это дает основание полагать, что полученные в результате проведенного исследования данные могут быть отнесены к лекарственно индуцированной патологии печени.

\section{Заключение}

Частые повторные введения местных анестетиков группы амидов в область головы и шеи более токсичны по сравнению с внутрибрюшинным введением, что подтверждается морфометрически выявленными статистически значимыми различиями ( $>>0,05)$. При введении МА в область головы и шеи рефлексотерапия оказывает достоверно более значимый гепатопротективный эффект, чем при внутрибрюшинном введении.

\section{Литература}

1. Корячкин, В. А. Нейроаксиальные блокады / В. А. Корячкин. - СПб. : ЭЛБИ-СПб, 2013. - 542 с.

2. Системная токсичность местных анестетиков при регионарной анестезии / В. А. Корячкин [и др.] // Регионар. анестезия и лечение острой боли. - 2015. - Т. 9, № 3. - С. 45-50.

3. Руководство по экспериментальному (доклиническому) изучению новых фармакологических веществ / под ред. Р. У. Хибриева. - М. : Медицина, 2005. $832 \mathrm{c}$.

4. Фесенко, В. С. Интоксикация местными анестетиками: старая опасность, современные мифы, новые препараты и «серебряная пуля» / В. С. Фесенко // Медицина неотлож. состояний. - 2008. - № 4. - С. 131-138.

5. Еремина, Е. Ю. Лекарственные поражения печени / Е. Ю. Еремина // Практ. медицина. Гастроэнтерология. - 2014. - № 1. - С. 23-33.

6. Чучула, Н. В. Местная анестезия у стоматологических пациентов группы риска / Н. В. Чучула, Е. Н. Чучула // Вісник ХНУ ім. В. Н. Каразіна. Сер. Медицина. - 2012. - № 24. - С. 99-104.

7. Денисов, С. Д. Требования к научному эксперименту с использованием животных / С. Д. Денисов // Здравоохранение. - 2001. - № 4. - С. 40-41.

8. Guide for the core and Use of Laboratory Animals / Committee for the Update of the Guide for the Care and Use of Laboratory Animals, Institute for Laboratory Animal Research, Division on Earth and Life Studies. - Washington : National Academy Press, 1996. - 246 p.

9. Руководство по лабораторным животным и альтернативным моделям в биомедицинских технологиях / ред.: Н. Н. Каркищенко, С. В. Грачев. - М. : Профиль, 2010. - $358 \mathrm{c}$.

10. Автандилов, Г. Г. Медицинская морфометрия : руководство / Г. Г. Автандилов. - М. : Медицина, 1990. $-384 \mathrm{c}$.

11. Реброва, О. Ю. Статистический анализ медицинских данных. Применение пакета прикладных программ STATISTICA / О. Ю. Реброва. - М. : Медиа Сфера, 2002. - $312 \mathrm{c}$.

12. Курс лекций по патологической анатомия : част. курс / под ред. М. А. Пальцева. - М., 2003. - 753 с.

13. Лекарственно-индуцированное поражение печени. Диагностика и лечение / А. В. Ковтун [и др.] // Лечащий врач. - 2011. - № 2. - С. 16-20.

14. Prediction of Drug-Induced Liver Injury in HepG2 Cells Cultured with Human Liver Microsomes / J. M. Choi [et al.] // Chem. Res. Toxicol. - 2015 May. - Vol. 28, N 5. - P. 872-885.

15. Drug-induced Liver Injury with HHV-6 Reactivation / M. Fujita [et al.] // Intern. Med. - 2015. - Vol. 54, N 10. - P. 1219-1222. 


\section{References}

1. Koryachkin VA. Neuroaxial blockades. Saint Petersburg, RF: ELBI-SPb; 2013. 542 p. (In Russ.)

2. Koryachkin VA, Geraskov EV, Kazarin VS, Liskov MA, Mokhanna M, Maltsev MP, i dr. Systemic toxicity of local anesthetics at a regional anesthesia. Regionar Anesteziia i Lechenie Ostroi Boli. 2015;9(3):45-50. (In Russ.)

3. Khibriev RU, red. Guide to experimental (preclinical) studying of new pharmacological substances. Moscow, RF: Meditsina; 2005. 832 p. (In Russ.)

4. Fesenko VS. Intoxication local anesthetics: old danger, current myths, new drugs and «a silver bullet». Meditsina Neotlozh Sostoianii. 2008;(4):131-8. (In Russ.)

5. Eremina EYu. Drug-induced injury of a liver. Prakt Meditsina Gastroenterologiia. 2014;(1):23-33. (In Russ.)

6. Chuchula NV, Chuchula EN. Local anesthesia in stomatologic patients of risk group. Visnik KhNU im VN Karazina Ser Meditsina. 2012;(24):99-104. (In Russ.)

7. Denisov SD. Demands to a scientific experiment with the use of animals. Zdravookhranenie. 2001;(4):40-1. (In Russ.)

8. Committee for the Update of the Guide for the Care and Use of Laboratory Animals, Institute for Laboratory Animal Research, Division on Earth and Life Studies. Guide for the core and Use of Laboratory Animals.
Washington: National Academy Press; 1996. 246 p.

9. Karkishchenko NN, Grachev SV, red. The guideline on laboratory animals application and alternative models in biomedical technologies. Moscow, RF: Profil'; 2010. 358 p. (In Russ.)

10. Avtandilov GG. Medical morphometry: rukovodstvo. Moscow, RF: Meditsina; 1990. 384 p. (In Russ.)

11. Rebrova OYu. Statistical analysis of medical data. Use of a package of application programs of STATISTICA. Moscow, RF: Media Sfera; 2002. 312 p. (In Russ.)

12. Paltsev MA, red. A course of lectures on pathological anatomy: chast kurs. Moscow, RF; 2003. 753 p. (In Russ.)

13. Kovtun AV, Yakovenko AV, Ivanov AN, Obukhovskiy BI, Soluyanova IP, Krasnolobova LP, i dr. Druginduced liver damage. Diagnosis and treatment. Diagnostika i lechenie. Lechashchii Vrach. 2011;(2):1620. (In Russ.)

14. Choi JM, Oh SJ, Lee JY, Jeon JS, Ryu CS, Kim YM, et al. Prediction of Drug-Induced Liver Injury in HepG2 Cells Cultured with Human Liver Microsomes. Chem Res Toxicol. 2015 May;28(5):872-85. doi: 10.1021/ tx500504n

15. Fujita M, Takahashi A, Imaizumi H, Hayashi M, Okai K, Kanno Y, et al. Drug-induced Liver Injury with HHV-6 Reactivation. Intern Med. 2015;54(10):1219-22. doi: 10.2169/internalmedicine.54.4329

Submitted 17.06.2016 Accepted 13.10.2016

\section{Сведения об авторах:}

Максимович Е.В. - ассистент кафедры хирургической стоматологии, Белорусский государственный медицинский университет;

Походенько-Чудакова И.О. - д.м.н., профессор, заведующая кафедрой хирургической стоматологии, Белорусский государственный медицинский университет.

\section{Information about authors:}

Maksimovich E.V. - teacher of the Chair of Surgical Dentistry, Belarusian State Medical University;

Pokhodenko-Chudakova I.O. - Doctor of Medical Sciences, professor, head of the Chair of Surgical Dentistry, Belarusian State Medical University.

Адрес для корреспонденции: Республика Беларусь, 210116, г. Минск, пр. Дзержинского, 83, Белорусский государственный медицинский университет, кафедра хирургической стоматологии. E-mail: ip-c@yandex.ru - Походенько-Чудакова Ирина Олеговна.

Correspondence address: Republic of Belarus, 210116, Minsk, 83 Dzerzhinsky ave., Belarusian State Medical University, Chair of Surgical Dentistry.E-mail: ip-c@yandex.ru-Pokhodenko-Chudakova Irina O. 